\title{
Low female birth weight and advanced maternal age programme alterations in next-generation blastocyst development
}

\author{
Jordanna S Master ${ }^{1}$, George A Thouas ${ }^{2}$, Alexandra J Harvey², John R Sheedy ${ }^{2}$, Natalie J Hannan ${ }^{2,3}$, \\ David K Gardner ${ }^{2}$ and Mary E Wlodek ${ }^{1}$ \\ ${ }^{1}$ Department of Physiology and ${ }^{2}$ School of BioSciences, The University of Melbourne, Parkville, Victoria 3010, \\ Australia and ${ }^{3}$ Department of Obstetrics and Gynaecology, Mercy Hospital, The University of Melbourne, \\ Heidelberg, Victoria 3084, Australia
}

Correspondence should be addressed to M E Wlodek; Email: m.wlodek@unimelb.edu.au

\begin{abstract}
Low birth weight is associated with an increased risk for adult disease development with recent studies highlighting transmission to subsequent generations. However, the mechanisms and timing of programming of disease transmission to the next generation remain unknown. The aim of this study was to examine the effects of low birth weight and advanced maternal age on second-generation preimplantation blastocysts. Uteroplacental insufficiency or sham surgery was performed in late-gestation WKY pregnant rats, giving rise to first-generation (F1) restricted (born small) and control offspring respectively. F1 control and restricted females, at 4 or 12 months of age, were naturally mated with normal males. Second-generation (F2) blastocysts from restricted females displayed reduced expression of genes related to growth compared with F2 control $(P<0.05)$. Following $24 \mathrm{~h}$ culture, F2 restricted blastocysts had accelerated development, with increased total cell number, a result of increased trophectoderm cells compared with control $(P<0.05)$. There were alterations in carbohydrate and serine utilisation in F2 restricted blastocysts and F2 restricted outgrowths from 4-month-old females respectively $(\boldsymbol{P}<\mathbf{0 . 0 5})$. F2 blastocysts from aged restricted females were developmentally delayed at retrieval, with reduced total cell number attributable to reduced trophectoderm number with changes in carbohydrate utilisation $(P<0.05)$. Advanced maternal age resulted in alterations in a number of amino acids in media obtained from F2 blastocyst outgrowths $(P<0.05)$. These findings demonstrate that growth restriction and advanced maternal age can alter F2 preimplantation embryo physiology and the subsequent offspring growth.
\end{abstract}

Reproduction (2015) 149 497-510

\section{Introduction}

Intrauterine growth restriction, characterised by birth weight below the 10th percentile for gestational age, complicates $\sim 10 \%$ of all pregnancies in the Western world and is commonly caused by placental dysfunction during late gestation (Barker 1995, McMillen \& Robinson 2005). Epidemiological studies have highlighted that being born small is associated with an increased disease risk not only for that individual, but also for subsequent generations of offspring (Heijmans et al. 2008, Painter et al. 2008). It has been reported that first-generation (F1) women, who themselves were undernourished in utero and born small, delivered smaller second-generation (F2) babies with an increased risk of developing hypertension, cardiovascular disease, impaired glucose tolerance and obesity in adult life (Heijmans et al. 2008, Painter et al. 2008). The pathways hypothesised to regulate transmission of disease risk include direct effects on germ cells from the F1 fetus, by inheritance through persistent epigenetic modifications of either of the parental germ cells, and/or abnormal pregnancy adaptations (Gallo et al. 2012a). However, it is unclear whether early changes in F2 physiology can be detected.

The blastocyst stage represents an early developmental window where reprogramming can occur (Watkins et al. 2008a). Before implantation, the blastocyst moves through the female reproductive tract bathed in nutrients from the surrounding maternal microenvironment and is therefore sensitive to changes in secretions in the maternal milieu. The primary sources of energy for the embryo from fertilisation to compaction are pyruvate, lactate and non-essential amino acids, while after compaction development, the utilisation of glucose and both essential and non-essential amino acids becomes increasingly important (Hardy et al. 1989, Brison \& Leese 1991, Lane \& Gardner 1997, Gardner 1998). Alterations in metabolic control during 
pregnancy, as reported in late gestation F1 female growth-restricted offspring (Gallo et al. 2012b), may be apparent earlier in development and alter nutrient availability to the developing F2 blastocyst before implantation. These changes may lead to subsequent alterations in growth and development of the fetus and placenta. The blastocyst comprises the inner cell mass (ICM) and the trophectoderm (TE), which give rise to the fetus and extra-embryonic tissues and placenta respectively. The placenta is an essential regulator of fetal growth during gestation, providing gas and nutrients to the developing fetus. Therefore, alterations caused by impaired TE development or function may affect placental development and therefore fetal nutrition and growth, leading to the programming of disease risk in the resultant progeny.

Several studies document clear alterations in F1 preimplantation embryo physiology and development that contribute to subsequent F1 health when an insult is experienced by the mother (F0) during pregnancy. Exposure of preimplantation mouse embryos to gestational diabetes leads to reductions in intracellular glucose and glucose utilisation, resulting from reductions in glucose uptake and expression of transporters at the mRNA and protein level in F1 preimplantation embryos (Moley et al. 1998). In a rat model of diabetes, high incidences of abnormal F1 preimplantation blastocysts have been reported, where only $33 \%$ of blastocysts reached the expanded blastocyst stage with a $20 \%$ reduction in ICM cell numbers (Lea et al. 1996). Similarly, studies examining the effect of maternal low-protein diet during early gestation (0-4.25 days) in rats have reported F1 female offspring born of low birth weight, accelerated postnatal growth in both F1 male and female offspring, and the development of hypertension in F1 male offspring (Kwong et al. 2000). Assessment of the early-stage F1 preimplantation blastocyst revealed a reduction in ICM number followed by reduced ICM and TE cell number at the expanding blastocyst stage due to slowed proliferation (Kwong et al. 2000). It was concluded that due to a mildly hyperglycaemic and amino acid-depleted maternal environment, maternal undernutrition may programme metabolic stress within the blastocyst.

Abnormal glucose metabolism in the mouse blastocyst has been linked to decreased developmental and implantation potential (Lane \& Gardner 1996). Provision of adequate glucose and amino acids in combination is beneficial to blastocyst development, ICM number and post-transfer fetal development, indicating that blastocyst nutrition is highly responsive to environmental metabolites. Amino acids and vitamins prevent metabolic perturbations and the associated loss of viability of mouse blastocysts (Lane \& Gardner 1998). Studies have highlighted that physiological changes occur within the preimplantation blastocyst to stabilise fetal growth and promote postnatal fitness in response to maternal low-protein diet during pregnancy
(Watkins et al. 2008b,c). The majority of embryo programming studies have, however, focused on alterations in F1 embryos and F1 offspring health. Few studies have characterised alterations in embryo growth and development in the next (F2) generation.

Our established rat model of uteroplacental insufficiency mimics intrauterine growth restriction similar to that observed in the Western world (Wlodek et al. 2005, 2008). Both F1 male and female offspring have organ deficits, but only F1 male offspring develop hypertension and metabolic dysfunction in adult life (Wadley et al. 2008, Wlodek et al. 2008, Moritz et al. 2009). During late gestation, F1 female growth-restricted offspring become glucose intolerant, develop glomerular hypertrophy and have modifications in uterine artery function (Mazzuca et al. 2010, Gallo et al. 2012 b). Alterations in the intrauterine nutrient environment caused by glucose intolerance may compromise F2 embryonic and fetal development, and therefore programme disease development in that generation, particularly affecting germ cell development. Altered fetal growth induced by uteroplacental insufficiency programmes F2 nephron and $\beta$-cell mass deficits, as well as hypertension and metabolic dysfunction in F2 offspring in the absence of low F2 birth weight (Anderson et al. 2006, Bertram et al. 2008, Torrens et al. 2008, Gallo et al. 2012 b, 2013, Tran et al. 2013). These studies highlight that the maternal metabolic environment may significantly affect the development of the blastocyst before implantation.

Increasing age has also been strongly associated with decreased fertility in humans, leading to recurrent pregnancy loss or complications (Gindoff \& Jewelewicz 1986). Maternal age, particularly after 35 years, is also associated with decreased ovarian reserve and increased rates of aneuploidy and chromosomal abnormality in their oocytes and cleavage stage preimplantation embryos (Munne et al. 1995, 2007, Harton et al. 2013). Murine models are in agreement with these changes, as increasing maternal age is related to increased rates of embryo fragmentation, although rodents do not show the same dramatic decline as humans in reproductive performance (Jurisicova et al. 1998). Maternal age, in both species, is, however, related to gestational factors such as increased placental weight (Haavaldsen et al. 2011, Gallo et al. 2012c). In recent studies of advanced maternal age, we have demonstrated that this parameter leads to a similar increase in placental weight at embryonic (E) day 20, followed by reduced litter size and birth weight (Gallo et al. 2012c). However, the effect of advanced maternal age on next-generation blastocyst morphology, carbohydrate utilisation, outgrowth potential and amino acid utilisation is yet to be addressed.

Therefore, the aims of this study were to assess blastocyst growth and development, metabolism and function of F2 preimplantation rat blastocysts derived from F1 growthrestricted females induced by uteroplacental insufficiency, and to examine the effect of age on preimplantation 
blastocyst development and viability. We propose that adverse pregnancy adaptations, such as glucose intolerance and glomerular hypertrophy, in female offspring born small would lead to alterations in the development and metabolism of their preimplantation blastocysts, which may affect growth and development of offspring in the next generation.

\section{Materials and methods}

Unless otherwise stated, chemicals were obtained from Sigma.

\section{Mating and animal generation}

This study was approved by the University of Melbourne Animal Ethics Experimentation Committee before all experimental procedures were carried out (AEC 1112128). A vaginal impedance reader (model MK-10B, Mukomachi Kikai, Osaka, Japan) was used to determine the time of oestrus for mating as described previously (Wlodek et al. 2005, 2008). Female WKY rats (F0) were mated between 18 and 24 weeks of age. On day 18 of gestation, rats underwent sham (control) or bilateral uterine vessel ligation (restricted) surgery (Wlodek et al. 2005, 2008). Rats gave birth naturally at term (day 22) to F1 control and growth-restricted offspring (born small) respectively. After weaning, day 35, F1 females were removed from F0 mothers and housed with one to two other females until the time of mating. Body weights and dimensions were measured in F1 females at day 1, day 7, day 35, 2 months, 3 months and 4 months of age (Wlodek et al. 2007).

F1 control and restricted females, at 4 months ( $n=10 /$ group) or 12 months (aged line) ( $n=10 /$ group) of age at oestrus, were naturally mated with normal (F0) males. For all experimental groups, one female per litter was used. Three sets of females were generated for gene analyses ( $n=6$ /group; performed in the 4-month cohort only), blastocyst morphology and carbohydrate utilisation ( $n=6$ /group) and outgrowth and amino acid utilisation ( $n=6$ /group). Mating success was confirmed by the presence of a vaginal plug after mating, and the following morning was considered day 0.5 of pregnancy. All female body weights and dimensions were measured before mating and at postmortem (day 4.5 of pregnancy) (Wlodek et al. 2005, 2008) after they were killed by $\mathrm{CO}_{2}$ inhalation. Plasma insulin concentrations were measured in duplicate using a rat insulin RIA kit (Millipore, Abacus ALS, Brisbane, QLD, Australia) (Tran et al. 2013). Plasma glucose concentrations were measured in duplicate using a scaled-down version of the enzymatic fluorometric analysis (Tran et al. 2013).

\section{$\mathrm{RT}^{2}$ profiler PCR array analysis}

Total RNA was extracted from three independent biological replicates of blastocysts using the Roche Total RNA Isolation Kit (Roche) according to the manufacturer instructions performed in the 4-month cohort only. There were six females per group and 10-20 blastocysts were pooled from two mothers resulting in three independent biological replicates per group. Briefly, samples were lysed and bound to a silica-based filter where they were treated with RNase-free DNase I (Roche), then washed with the kit buffer before elution in $50 \mu$ l of the kit elution buffer. RNA concentration was assessed using a NanoDrop absorbance spectrophotometer (ND1000, Thermo Scientific, Waltham, MA, USA) and RNA integrity was evaluated with the Agilent 2100 Bioanalyzer using a RNA 6000 Nano Assay Kit (Agilent Technologies, Santa Clara, CA, USA). RNA was converted to cDNA using the $\mathrm{RT}^{2}$ First Strand cDNA synthesis kit (Qiagen), and amplified using a $\mathrm{RT}^{2}$ PreAMP CDNA synthesis kit (Rat mTOR Signalling PCR array and Rat Insulin Signalling Pathway PCR array, Qiagen) according to the manufacturer's instructions. Gene expression of mammalian target of rapamycin (mTOR) (84 genes in total, data not shown) and insulin signalling (84 genes in total, data not shown) pathways were analysed on respective $\mathrm{RT}^{2}$ Profiler Arrays (Qiagen). Amplification was performed on an ABI Viia7 (Applied Biosystems Life Technologies) with the resultant gene expression analysed using the Web-based PCR Array Data Analysis software (www. SAbiosciences.com). All significant gene expression data, summarised in the $\mathrm{PI} 3 \mathrm{~K}, \mathrm{PKB} / \mathrm{AKT}$, growth and motility and metabolism and inflammation pathways, are presented and include other relevant genes in the respective pathways.

\section{Blastocyst flushing and culture}

Day 4.5 blastocysts were retrieved from intact uteri by flushing with laboratory-made MOPS buffered G2 medium modified for the rat by increasing the osmolality to $310 \mathrm{mOsmol} / \mathrm{kg}$ using $\mathrm{NaCl}$, as described previously ( $n=30-60$ blastocysts/group from $n=6$ females/group) (Oh et al. 1998, Gardner \& Lane 2014). Blastocysts from F1 control and restricted females were then cultured in laboratory-made $\mathrm{NaHCO}_{3}$-buffered G2 medium (Gardner \& Lane 2014) also with modified osmolality, supplemented with $5 \mathrm{mg} / \mathrm{ml}$ human serum albumin (HSA, Vitrolife, Västra Frölunda, Göteburg, Sweden) under paraffin oil (Ovoil, Vitrolife, Västra Frölunda) and housed in a dual gas incubator (ThermaForma, Mariette, $\mathrm{OH}, \mathrm{USA}$ ) at $37^{\circ} \mathrm{C}$, in an atmosphere of $6 \% \mathrm{CO}_{2}, 5 \% \mathrm{O}_{2}$ and $89 \% \mathrm{~N}_{2}$, for $24 \mathrm{~h}$ (Oh et al. 1998, Lane \& Gardner 2004, Gardner \& Lane 2007). F2 blastocysts were scored for the stage of development at flushing and again after the $24 \mathrm{~h}$ culture period, according to a numerical grade based on blastocyst morphology (grade 3, early blastocyst; grade 4, expanded blastocyst; grade 5, hatching blastocyst and grade 6, fully hatched blastocyst) (Gardner et al. 2000). Following $24 \mathrm{~h}$ culture, preimplantation blastocysts were prepared for differential nuclear staining or outgrowth culture.

\section{Differential nuclear staining}

Total cell number and the proportion of TE and ICM cells were assessed in F2 rat blastocysts using a modification of a method described previously ( $n=30-60$ blastocysts/group from $n=6$ females/group) (Handyside \& Hunter 1984, Hardy et al. 1989). Briefly, blastocysts were incubated in pronase (Sigma, $0.5 \%$ in GMOPS, $5 \mathrm{~min}$ at $37^{\circ} \mathrm{C}$ ) to remove the zona pellucida, then incubated in picrylsulfonic acid (Sigma, $10 \mathrm{~min}$ at $37^{\circ} \mathrm{C}$ ) and washed in GMOPS with $5 \mathrm{mg} / \mathrm{ml}$ HSA. Embryos were then incubated in anti-dinitrophenol (Sigma, $10 \mathrm{~min}$ at $37^{\circ} \mathrm{C}$ ) followed by washing in GMOPS supplemented with $5 \mathrm{mg} / \mathrm{ml} \mathrm{HSA}$. 
Complement-mediated lysis was performed by a short incubation in guinea pig serum (IMVS, Adelaide, SA, Australia, $10 \mathrm{~min}$ ) before transfer to a bisbenzimide solution of $0.1 \mathrm{mg} / \mathrm{ml}$ (Hoescht 33 342, Sigma). Blastocysts were then mounted in glycerol and nuclei counted under u.v. light (filter) using an inverted microscope (TS100-F, Nikon, Yamato, Kanagawa, Japan).

\section{Blastocyst glucose consumption and lactate production quantification}

Spent culture medium samples were stored at $-80{ }^{\circ} \mathrm{C}$ following $24 \mathrm{~h}$ of incubation with individual F2 blastocysts $(n=30-60$ blastocysts/group from $n=6$ females/group). Glucose and lactate concentrations were measured using enzyme-linked assays described by Gardner \& Leese (1987) and Gardner (2007). F2 blastocysts were first incubated in $4 \mu$ drops of incubation medium, comprising $\mathrm{HCO}_{3}^{-}$buffered G2 formulated with $0.5 \mathrm{mM}$ glucose as the sole substrate and no added lactate or pyruvate. Following the 24-h incubation, glucose consumption and lactate production were quantitated per embryo using a NanoDrop fluorospectrometer (ND3300, Thermo Scientific) (expressed in mol) and normalised to the number of cells per embryo to account for differences in blastocyst cell numbers. Glycolytic activity (lactate:glucose per cent ratio) of each embryo was calculated on the assumption that 2 mol of lactate are formed from 1 mol of glucose (Lane \& Gardner 1996).

\section{Blastocyst outgrowth culture}

Outgrowths in F2 blastocysts were performed as described previously ( $n=10-40$ blastocysts/group from $n=6$ females/ group) (Hannan et al. 2011). Flat-bottomed 96-well plates (BD Biosciences, San Jose, CA, USA) were coated with fibronectin (10 $\mu \mathrm{g} / \mathrm{ml}$; Sigma) and incubated with $4 \mathrm{mg} / \mathrm{ml}$ BSA (Sigma) for $1 \mathrm{~h}$. Wells were washed and filled with $150 \mu \mathrm{l}$ of a modified G2 medium supplemented with $5 \mathrm{mg} / \mathrm{ml} \mathrm{HSA}$ (Vitrolife, Västra Frölunda) and equilibrated at $37^{\circ} \mathrm{C}$ under paraffin oil for $3 \mathrm{~h}$. Hatched blastocysts were placed individually into coated wells and incubated for a period of $66 \mathrm{~h}$. Blastocyst outgrowth was examined through the acquisition of images taken at $10 \times$ magnification at 4, 18, 23, 28, 42, 47, 52 and 66 h time-points during culture, using an inverted microscope equipped with a heated stage at $37^{\circ} \mathrm{C}$ (Eclipse TS100-F, Nikon). The area of outgrowth was measured in each image using the NIS Elements BR 3.00, SP7 Laboratory Imaging software (Nikon). All images were analysed at matching magnification $(\times 10)$. The average area of outgrowth was calculated for each treatment and repeated three times. At the completion of culture ( $66 \mathrm{~h}$ post-transfer), $100 \mu$ of outgrowth media were collected for NMR analysis.

\section{Metabolomic analysis of culture media}

Outgrowth media were analysed for carbohydrate and amino acid composition by ${ }^{1} \mathrm{H}-\mathrm{NMR}$ spectroscopy $(n=10-40$ blastocysts/group from $n=6$ females/group). Chilled methanol measuring $140 \mu \mathrm{l}$ was added to $70 \mu \mathrm{l}$ aliquots of spent outgrowth medium from F2 control and restricted blastocyst cultures, and incubated on ice for $15 \mathrm{~min}$ (Sheedy et al. 2010, Gook et al. 2014). Samples were then centrifuged at $5000 \mathrm{~g}$ for $15 \mathrm{~min}$.
A $160 \mu \mathrm{l}$ aliquot of supernatant was collected and dried under speed vacuum for $12 \mathrm{~h}$ at $45^{\circ} \mathrm{C}$. Samples were then resuspended in $540 \mu \mathrm{l}$ of $200 \mathrm{mM}$ of trisodium phosphate in deuterium oxide $\left(\mathrm{Na}_{3} \mathrm{PO}_{4} \cdot \mathrm{D}_{2} \mathrm{O}\right.$, titrated to $\mathrm{pH} 7$ with $\mathrm{DCl}$ ) (Sigma and Cambridge Isotope Laboratories, Inc., Andover, MA, USA). An additional $60 \mu \mathrm{l}$ of $5 \mathrm{mM}$ 2,2-dimethylsilyl-2-propane sulfonic acid (DSS $\cdot \mathrm{D}_{2} \mathrm{O}$, Cambridge) was added as a standard for determining concentrations of medium components. The $600 \mu \mathrm{l}$ final sample volume was added to $5 \mathrm{~mm} 507$ grade glass NMR tubes (Wilmad LabGlass, Vineland, NJ, USA) before spectral acquisition.

Samples were analysed on a $600 \mathrm{MHz}$ Bruker Avance US ${ }^{2}$ (Bruker BioSpin Pty Ltd., Alexandria, NSW, Australia) spectrometer equipped with a $5 \mathrm{~mm}$ triple resonance cryoprobe. Samples were locked to deuterium $\left(\mathrm{D}_{2} \mathrm{O}\right)$ and gradient shimmed. The $90^{\circ}$ pulse width was calibrated and receiver gain optimised for each sample. Spectra were collected over $64 \mathrm{k}$ data points and 256 scans. A one-dimensional nuclear overhauser spectrometry pulse sequence with presaturation (noesypr1d) for water suppression was used (recycle delay- $90^{\circ}-\tau-90^{\circ}-\tau_{\mathrm{m}}-90^{\circ}$-acquire FID), with a recycle delay of $1.5 \mathrm{~s}$, mixing time $\left(\tau_{\mathrm{m}}\right)$ of $50 \mu \mathrm{s}$ and transmitter frequency offset of $2848 \mathrm{~Hz}$. Spectra were Fourier transformed and phase corrected, and calibrated to the DSS signal at $0.00 \mathrm{ppm}$. A line-broadening factor of $0.5 \mathrm{~Hz}$ was applied to all spectra. Processed NMR spectra were imported into the Chenomx NMR Suite v. 5.1 (Chenomx, Inc., Edmonton, AB, Canada) and medium components were identified and quantified using the $600 \mathrm{MHz}$ compound library. The NMR data acquisition and processing parameters were selected to maintain compatibility with the Chenomx metabolite library as described previously (Sheedy et al. 2010).

\section{Statistical analyses}

All developmental, gene expression and microfluorescence data were analysed using a two-way ANOVA (SPSS, Inc.) to determine the main effects of experimental groups. If a significant interaction was detected, the Mann-Whitney's $U$ tests (SPSS, Inc.) were performed for post hoc comparisons. For all NMR data, metabolite concentrations were normalised by blastocyst outgrowth area (Constant Sum normalisation) to correct for differences in metabolic flux due to blastocyst size (Webb-Robertson et al. 2005, Craig et al. 2006). As outgrowths can have bi/multi-nucleated cells, cell number estimation may be inaccurate. A data matrix of quantified metabolites from ${ }^{1} \mathrm{H}$-NMR spectral analysis of all samples was created. Scedasticity was corrected using $\log _{10}$ transformation. All data were analysed using a two-way ANOVA (SPSS, Inc.) to determine the main effects of experimental groups. If a significant interaction was detected, the Mann-Whitney's $U$ tests (SPSS, Inc.) were performed for post hoc comparisons. In addition, the Mann-Whitney's $U$ tests (SPSS, Inc.) were conducted to determine significant interactions between experimental groups F2 control and restricted outgrowth medium samples from 4- and 12-month-old F1 females. Metabolite concentrations are expressed as $\mu \mathrm{M} /\left(\right.$ pixel $\left.^{2} \times 10^{3}\right) \pm$ S.E.M. with metabolite concentrations expressed as production (positive values) or consumption (negative values) relative to the control medium sample. All data are expressed as means \pm s.E.M. and $P<0.05$ was considered statistically significant. 
Table 1 F1 female body and organ weights.

\begin{tabular}{|c|c|c|c|c|c|c|c|}
\hline & \multicolumn{2}{|c|}{ 4-month cohort } & \multicolumn{2}{|c|}{ 12-month cohort } & \multicolumn{3}{|c|}{ Two-way ANOVA } \\
\hline & Control & Restricted & Control & Restricted & Group & Cohort & Interaction \\
\hline \multicolumn{8}{|c|}{ Body weight (g) } \\
\hline Day 1 & $4.27 \pm 0.08$ & $3.73 \pm 0.10$ & $4.49 \pm 0.08$ & $3.65 \pm 0.09$ & 0.0001 & NS & NS \\
\hline Day 7 & $10.69 \pm 0.34$ & $8.72 \pm 0.67$ & $10.29 \pm 0.63$ & $9.01 \pm 0.67$ & 0.017 & NS & NS \\
\hline Day 14 & $22.61 \pm 0.67$ & $19.45 \pm 1.52$ & $23.19 \pm 0.84$ & $21.18 \pm 1.07$ & 0.044 & NS & NS \\
\hline Day 35 & $69.07 \pm 1.45$ & $65.32 \pm 3.23$ & $79.29 \pm 2.53$ & $74.91 \pm 2.27$ & NS & 0.0001 & NS \\
\hline 2 months & $147.12 \pm 2.13$ & $146.71 \pm 5.76$ & $165.11 \pm 6.20$ & $156.87 \pm 6.83$ & NS & 0.012 & NS \\
\hline 3 months & $199.35 \pm 4.01$ & $189.41 \pm 4.63$ & $206.52 \pm 6.88$ & $197.03 \pm 6.40$ & NS & NS & NS \\
\hline 4 months & $214.98 \pm 2.91$ & $205.07 \pm 5.92$ & $221.17 \pm 4.79$ & $216.79 \pm 5.62$ & NS & NS & NS \\
\hline \multicolumn{8}{|c|}{ Relative organ weight $(\%)$} \\
\hline Heart & $0.42 \pm 0.01$ & $0.39 \pm 0.01$ & $0.99 \pm 0.02$ & $0.37 \pm 0.01$ & NS & 0.002 & NS \\
\hline Kidney & $0.67 \pm 0.01$ & $0.64 \pm 0.01$ & $0.65 \pm 0.02$ & $0.61 \pm 0.02$ & 0.008 & 0.016 & NS \\
\hline Liver & $4.60 \pm 0.18$ & $4.44 \pm 0.08$ & $4.02 \pm 0.27$ & $3.97 \pm 0.24$ & NS & 0.003 & NS \\
\hline Pancreas & $0.26 \pm 0.01$ & $0.31 \pm 0.04$ & $0.73 \pm 0.06$ & $0.32 \pm 0.04$ & NS & NS & NS \\
\hline Mammary & $0.25 \pm 0.03$ & $0.17 \pm 0.03$ & $0.32 \pm 0.07$ & $0.18 \pm 0.03$ & 0.015 & NS & NS \\
\hline Dorsal fat & $1.21 \pm 0.06$ & $1.15 \pm 0.04$ & $4.02 \pm 0.94$ & $1.51 \pm 0.14$ & NS & NS & NS \\
\hline Uterus & $0.14 \pm 0.01$ & $0.14 \pm 0.01$ & $0.15 \pm 0.01$ & $0.14 \pm 0.01$ & NS & NS & NS \\
\hline Ovary & $0.11 \pm 0.01$ & $0.11 \pm 0.01$ & $0.07 \pm 0.01$ & $0.07 \pm 0.01$ & NS & 0.0001 & NS \\
\hline
\end{tabular}

F1 body weight (from birth to 4 months of age) and organ weights at postmortem (relative to body weight; day 4.5 of pregnancy) from 4 - and 12 -month F1 control and restricted cohort. All data are expressed as mean \pm s.E.M., $n=10$ /group. $P<0.05$ vs control group (main effect). $P<0.05$ vs 4-month cohort (main effect).

\section{Results}

\section{Uteroplacental insufficiency affects physiology of F1 females}

F1 growth-restricted female offspring arising from F0 mothers that underwent bilateral uterine vessel ligation surgery were born small and remained $7-13 \%$ smaller at day 7 and day 14 compared with F1 control offspring $(P<0.05$; Table 1). The 12-month control and restricted cohort had a slight increase in body weight at 35 days and 2 months of age compared with the 4-month cohort, but there were no differences in body weight between F1 control and restricted females at 3 and 4 months of age in the 4- or 12-month cohort (Table 1). At postmortem, in the 4- and 12-month cohort, there were no differences in the relative heart, liver, pancreas, dorsal fat, uterus and ovary weights between $\mathrm{F} 1$ control and restricted females; however, the kidney and mammary weights were reduced in $\mathrm{F} 1$ restricted females $(P<0.05$; Table 1$)$. In the 12-month cohort compared with the 4-month cohort, regardless of growth restriction, $\mathrm{F} 1$ females had increased heart, kidney, liver and ovary weights $(P<0.05$; Table 1$)$. At mating, in the 4 - and 12-month cohort, no differences in maternal age, weight, basal plasma glucose, basal plasma insulin, mating success rate or the number of blastocysts collected were observed between F1 control and restricted females (Table 2). F1 females in the 12-month cohort had an increase in body weight and age compared with F1 females in the 4-month cohort $(P<0.05$; Table 2). These results were collected from females allocated to the cohort of blastocyst morphology and carbohydrate utilisation measures.

\section{Growth restriction of F1 females alters F2 blastocyst physiology}

The morphological stage of blastocyst development upon retrieval at day 4.5 of gestation was not significantly different between F2 control and restricted

Table 2 F1 maternal parameters at mating.

\begin{tabular}{|c|c|c|c|c|c|c|c|}
\hline & \multicolumn{2}{|c|}{ 4-month cohort } & \multicolumn{2}{|c|}{ 12-month cohort } & \multicolumn{3}{|c|}{ Two-way ANOVA } \\
\hline & Control & Restricted & Control & Restricted & Group & Cohort & Interaction \\
\hline Age (weeks) & $21.1 \pm 1.35$ & $20 \pm 0.91$ & $52 \pm 1.02$ & $52 \pm 1.53$ & NS & $P<0.0001$ & NS \\
\hline Weight (g) & $228.31 \pm 2.43$ & $217.21 \pm 3.01$ & $249.98 \pm 9.99$ & $259.58 \pm 6.97$ & NS & $P<0.0001$ & NS \\
\hline $\begin{array}{l}\text { Plasma glucose } \\
(\mathrm{mmol} / \mathrm{l})\end{array}$ & $17.51 \pm 2.21$ & $17.61 \pm 2.31$ & $13.72 \pm 1.08$ & $10.21 \pm 1.42$ & NS & NS & NS \\
\hline $\begin{array}{l}\text { Plasma insulin } \\
\qquad(\mathrm{ng} / \mathrm{ml})\end{array}$ & $1.65 \pm 0.17$ & $2.35 \pm 0.41$ & $2.03 \pm 0.33$ & $1.89 \pm 0.37$ & NS & NS & NS \\
\hline $\begin{array}{l}\text { Mating success } \\
\text { rate }\end{array}$ & $100 \%$ & $100 \%$ & $100 \%$ & $100 \%$ & NS & NS & NS \\
\hline $\begin{array}{l}\text { Blastocysts } \\
\text { collected }\end{array}$ & $8 \pm 0.41$ & $6 \pm 0.65$ & $7 \pm 1.85$ & $5 \pm 1.03$ & NS & NS & NS \\
\hline
\end{tabular}

Measurements were performed in 4 - and 12-month control and restricted cohorts. All data are expressed as mean \pm S.E.M., $n=10 /$ group. $P<0.05$ vs 4-month cohort (main effect). 

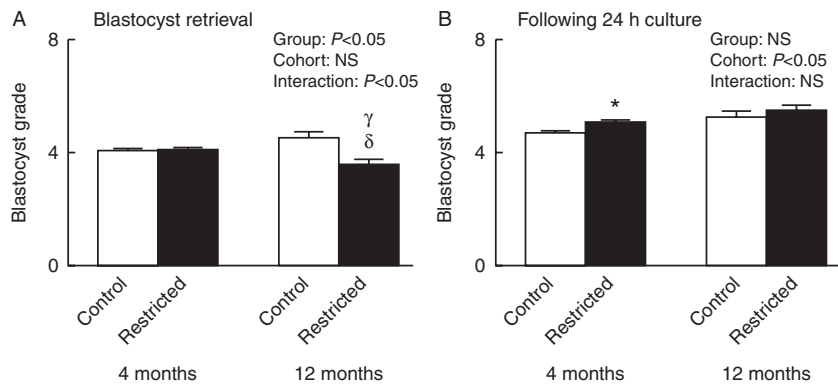

Figure $1 \mathrm{~F} 2$ blastocyst grade. F2 blastocysts at (A) retrieval (day 4.5) and (B) following $24 \mathrm{~h}$ culture from 4 - and 12-month control and restricted cohorts. All data are expressed as mean \pm s.E.M., $n=30-60$ blastocysts/group from $n=6$ females/group. $P<0.05$ vs control group (main effect). $P<0.05$ vs 4 -month cohort (main effect). ${ }^{\delta} P<0.05$ vs control group (following significant interaction). ${ }^{\gamma} P<0.05$ vs 4 -month cohort (following significant interaction). ${ }^{*} P<0.05$ vs control.

blastocysts from 4-month-old females (Fig. 1A). However, following $24 \mathrm{~h}$ of incubation in vitro, $\mathrm{F} 2$ restricted blastocysts, from 4-month-old females, displayed accelerated development, with a higher proportion of blastocysts developing to both the hatching and fully hatched blastocyst stages compared with control blastocysts, which remained at the hatching stage $(P<0.05$; Fig. 1B). F2 restricted blastocysts collected from 12-month-old (aged) F1 females were delayed in their development, with mostly early blastocysts observed on day 4.5 compared with control females, with collection of mostly expanded blastocysts after flushing $(P<0.05$; Fig. 1A). Following $24 \mathrm{~h}$ in vitro culture, there were no differences in development to the hatching blastocyst stage between F2 control and restricted blastocysts from 12-month-old females (Fig. 1B). F2 blastocysts from F1 aged females, however, were more advanced (developmental stage 5-6), irrespective of growth restriction, compared with blastocysts from 4-month-old females (developmental stage 4-5, $P<0.05$; Fig. 1B).

This growth acceleration in $\mathrm{F} 2$ restricted blastocysts from 4-month-old females was associated with a greater total cell number, compared with F2 control blastocysts, over the same $24 \mathrm{~h}$ period $(P<0.05 ;$ Fig. $2 \mathrm{~A})$. There was a greater TE cell number $(11 \%, P<0.05$; Fig. $2 \mathrm{~B})$, while ICM cell number remained constant (Fig. 2C). The proportion of ICM:TE was not different (data not shown). A lower total cell number and TE cell number was observed in F2 restricted blastocysts from aged F1 restricted females vs F2 control blastocysts (16-19\%, $P<0.05$; Fig. 2A and B). F2 control blastocysts from aged $\mathrm{F} 1$ females had a higher number of total and TE cells compared with control blastocysts from 4-month-old females $(P<0.05$; Fig. $2 \mathrm{~A}$ and $\mathrm{B})$. No differences in ICM cell number (Fig. 2C), or the ratio of ICM:TE cells (data not shown), were detected between F2 control or restricted blastocysts from either age group.

No differences were observed between F2 control and restricted blastocysts from 4-month-old females after the
$24 \mathrm{~h}$ incubation, in either glucose consumption per hour, or when normalised to the total cell number (Fig. 3A and B). However, a significant increase was detected in lactate production by F2 restricted blastocysts from 4-month-old females compared with F2 control
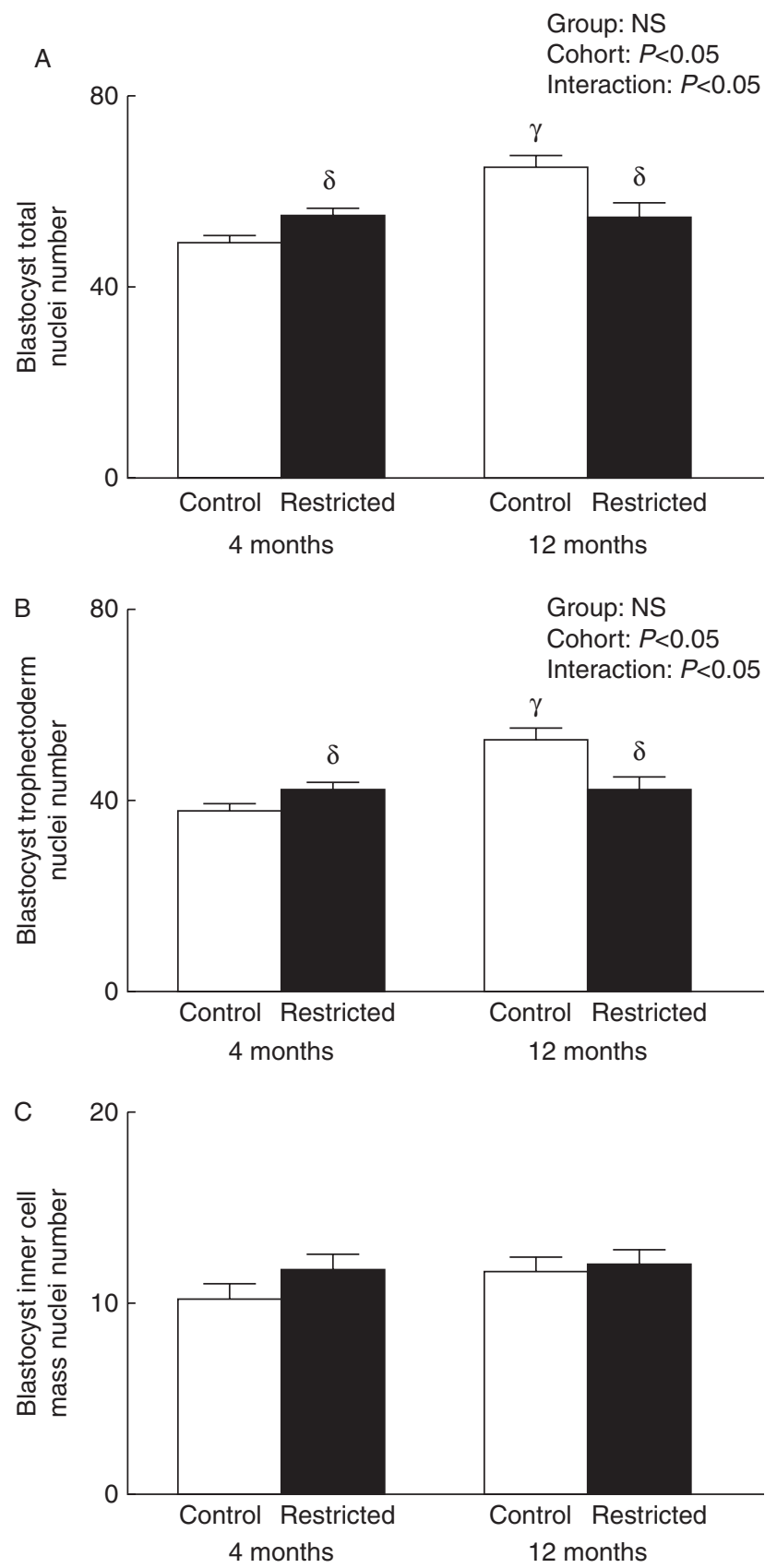

Figure 2 F2 blastocyst nuclei number. (A) Total nuclei number, (B) trophectoderm nuclei number and (C) inner cell mass nuclei number of F2 blastocysts following $24 \mathrm{~h}$ culture from 4- and 12-month F1 control and restricted cohorts. All data are expressed as mean \pm s.E.M., $n=30-60$ blastocysts/group from $n=6$ females/group. $P<0.05$ vs 4 -month cohort (main effect). ${ }^{\delta} P<0.05$ vs control group (following significant interaction). ${ }^{\gamma} P<0.05$ vs 4 -month cohort (following significant interaction). 

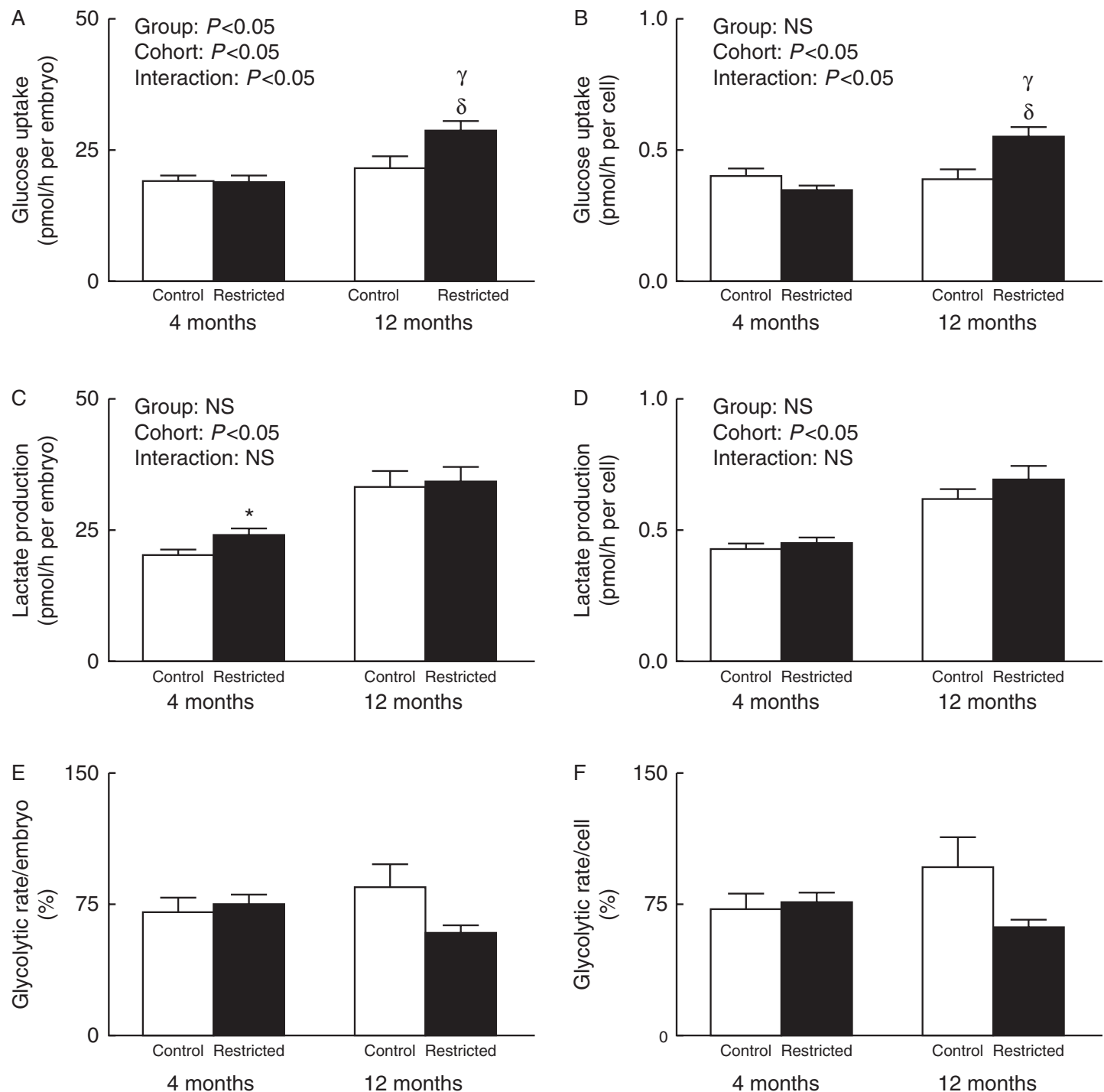

Figure 3 F2 carbohydrate consumption. (A) Glucose consumption per hour per blastocyst, (B) glucose consumption per hour per cell, (C) lactate production per hour per blastocyst, (D) lactate production per hour per cell, (E) glycolytic rate per hour per blastocyst and (F) glycolytic rate per hour per cell of F2 blastocysts following $24 \mathrm{~h}$ culture from 4 - and 12-month F1 control and restricted cohorts. All data are expressed as mean \pm s.E.M., $n=30-60$ blastocysts/group from $n=6$ females/group. $P<0.05$ vs control group (main effect). $P<0.05$ vs 4 -month cohort (main effect). ${ }^{\delta} P<0.05$ vs control group (following significant interaction). ${ }^{\gamma} P<0.05$ vs 4 -month cohort (following significant interaction). ${ }^{*} P<0.05$ vs control.

blastocysts $(P<0.05$; Fig. 3C), although this difference was not present when lactate production was expressed per cell. Glycolytic rate was not significantly different between F2 control and restricted blastocysts from 4-month-old females (Fig. 3E and F). An increase in glucose consumption per blastocyst was observed in F2 restricted blastocysts from aged F1 females, compared with the 12-month control and 4-month restricted groups at $24 \mathrm{~h}(P<0.05 ;$ Fig. 3A). This difference was maintained when glucose consumption was normalised to the total cell number $(P<0.05$; Fig. 3B). Neither lactate consumption nor glycolytic rate was significantly different between $\mathrm{F} 2$ restricted and control blastocysts from aged $\mathrm{F} 1$ females (Fig. 3C, D, E and F). However, lactate production per blastocyst and that per cell were both higher in the maternal 12-month cohort compared with the maternal 4-month cohort $(P<0.05$; Fig. $3 \mathrm{C}$ and $\mathrm{D})$.

Following outgrowth culture, all F2 blastocysts attached regardless of their maternal origin (from either 4- or 12-month-old F1 females). F2 blastocyst outgrowth area did not significantly differ between F2 control and restricted groups from 4 - and 12-month-old F1 females, at any of the time-points assessed (Fig. 4). There were no alterations in carbohydrate utilisation between F2 control and restricted outgrowths. Analysis of amino acid utilisation by F2 restricted outgrowths from 4-month-old females revealed an increase in lysine and serine consumption, and an increased production of 


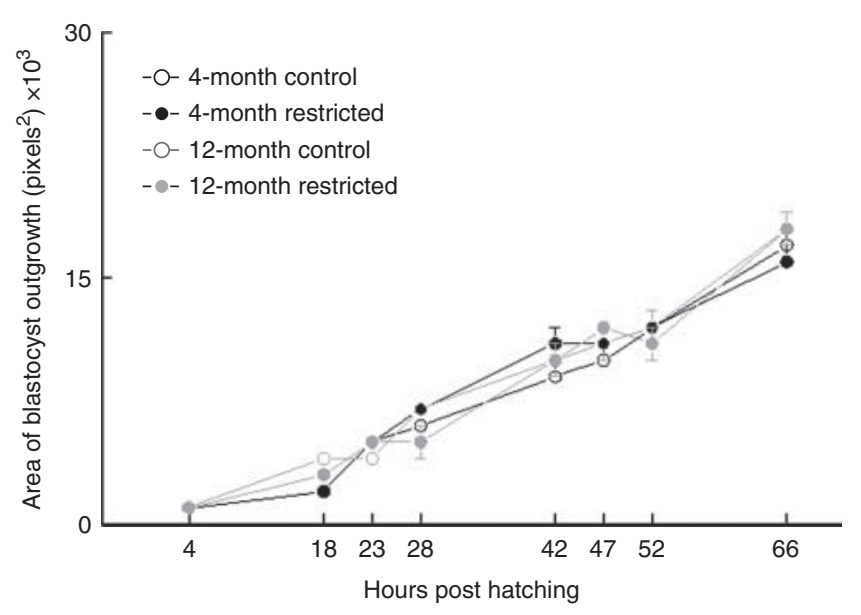

Figure 4 F2 blastocyst outgrowth. Measurements performed on F2 blastocysts ( $66 \mathrm{~h}$ outgrowth culture) following $24 \mathrm{~h}$ culture from 4 - and 12-month F1 control and restricted cohorts. Open circles represent F2 control blastocysts from 4-month F1 control females, closed circles represent F2 restricted blastocysts from 4-month F1 restricted females, grey open circles represent F2 control blastocysts from 12-month F1 control females and grey closed circles represent F2 restricted blastocysts from 12-month F1 restricted females. All data are expressed as mean \pm s.E.M., $n=10-40$ blastocysts/group from $n=6$ females/group.

histidine and glutamate compared with controls $(P<0.05$; Table 3$)$.

Glucose and lactate production was increased in outgrowths from F2 control and restricted blastocysts from aged females, while pyruvate production was reduced when compared with blastocysts from 4-month-old females at the end of outgrowth culture $(P<0.05$; Table 3$)$. Aspartate and serine consumption was increased in F2 restricted outgrowths from 12 -month-old females compared with control $(P<0.05$; Table 3$)$. Production of the amino acids isoleucine, methionine, glycine and proline was increased, while cysteine production was reduced $(P<0.05$; Table 3$)$ in outgrowths from 12 -month-old females. There was reduced consumption of arginine, leucine, valine and tyrosine in outgrowths from 12-month-old females $(P<0.05$; Table 3).

\section{Growth restriction of $\mathrm{F1}$ females alters F2 blastocyst gene expression dynamics}

Expression of genes involved in growth and insulin signalling pathways was significantly reduced on day 4.5 in F2 control and restricted blastocysts from 4-month-old females $(P<0.05$; Fig. 5; total of 168 genes targeted). Genes involved in PI3K signalling, Pik3ca and Pik3cb, had reduced expression in F2 restricted blastocysts compared with controls (26-32\%, $P<0.05$; Fig. 5A). Energy-sensing pathway genes, Prkag1, Prkcb, Tsc1, Rraga, Mtor and Ulk1, involved in PKB/Akt signalling, were significantly reduced in F2 restricted blastocysts (30-97\%, P<0.05; Fig. 5B). Expression of growth and motility genes Actb and $\mathrm{Prl}$ was reduced (31-53\%, $P<0.05$; Fig. 5C); however, Rras gene expression was significantly increased in $\mathrm{F} 2$ restricted blastocysts compared with controls $(110 \%, P<0.05$; Fig. 5C). F2 restricted blastocysts also displayed reduced expression of genes involved in metabolism, Ldha and Ucp1 (38-77\%, $P<0.05$; Fig. 5D) compared with maternal 4-month control blastocyst levels (Figure 4).

\section{Discussion}

This study identifies alterations in the expression of genes involved in growth and development pathways, accompanied by increased proliferation of the trophectoderm, altered lactate metabolism and amino acid consumption of serine by F2 blastocysts arising from females born small due to intrauterine growth restriction. Advanced maternal age alters F2 preimplantation blastocyst growth and development with alterations in blastocyst cell number as well as altered carbohydrate and amino acid metabolism in arginine, isoleucine, leucine, methionine, valine, cysteine, glycine, proline and tyrosine, compared with 4-month-old females. These data demonstrate that the next-generation preimplantation blastocyst is programmed via the maternal line of transmission and age. These alterations in blastocyst development and function may represent a mechanistic pathway contributing to the altered cardiovascular and metabolic phenotypes of next-generation F2 offspring, as reported previously (Gallo et al. 2012b,c, 2013).

\section{Uteroplacental insufficiency does not affect reproductive fitness of $F 1$ females}

The phenomenon of catch-up growth, with or without the combination of low birth weight, is known to programme disease development in offspring during adult life (Eriksson et al. 2001). In this study, F1 growthrestricted females were born small and displayed catchup growth to reach a similar weight to control animals, consistent with epidemiological and experimental evidence (McMillen \& Robinson 2005). F1 growthrestricted females have normal reproductive potential and basal glucose and insulin levels with unknown metabolic function. However, this is not indicative of changes that may be occurring in the uterine circulation and lumen. We have also previously reported no alterations in F2 litter size, which is indicative of maintenance of pregnancy by F1 growth-restricted females (Gallo et al. 2012b). While these experiments demonstrate that there are no differences in birth weight of F2 restricted offspring, cellular deficits and programming of metabolic disease and hypertension occur in a sex-specific manner in F2 offspring (Wlodek et al. 2008, Moritz et al. 2009, Mazzuca et al. 2010, Gallo et al. 2012b). Importantly, we have previously demonstrated loss of glucose tolerance during late gestation in F1 
Table 3 F2 outgrowth blastocyst nutrient utilisation.

\begin{tabular}{|c|c|c|c|c|c|c|c|}
\hline \multirow{2}{*}{$\begin{array}{l}\text { Metabolite } \\
(\text { pmol/blastocyst/h/ } \\
\left.\left(\text { pixels }^{2}\right) 10^{3}\right)\end{array}$} & \multicolumn{2}{|c|}{ 4-month cohort } & \multicolumn{2}{|c|}{ 12-month cohort } & \multicolumn{3}{|c|}{ Two-way ANOVA } \\
\hline & Control & Restricted & Control & Restricted & Group & Cohort & Interaction \\
\hline Glucose & $-28.72 \pm 8.15$ & $-20.15 \pm 5.64$ & $0.18 \pm 1.49^{\S}$ & $1.09 \pm 1.20^{\S}$ & NS & $P=0.003$ & NS \\
\hline Lactate & $-22.26 \pm 8.08$ & $-15.42 \pm 6.62$ & $8.74 \pm 1.87^{\S}$ & $10.08 \pm 2.12^{\S}$ & NS & $P=0.001$ & NS \\
\hline Pyruvate & $0.41 \pm 0.10$ & $0.30 \pm 0.09$ & $0.05 \pm 0.02^{\S}$ & $0.03 \pm 0.02^{\S}$ & NS & $P=0.004$ & NS \\
\hline \multicolumn{8}{|l|}{ Essential amino acids } \\
\hline Arginine & $-2.94 \pm 1.26$ & $-3.64 \pm 0.61$ & $-0.55 \pm 0.90$ & $-1.28 \pm 0.38^{\S}$ & NS & $P=0.048$ & NS \\
\hline Histidine & $-0.44 \pm 0.20$ & $0.26 \pm 0.22 *$ & $0.19 \pm 0.16^{+}$ & $-0.03 \pm 0.05$ & NS & NS & $P=0.049$ \\
\hline Isoleucine & $-1.58 \pm 0.41$ & $-1.67 \pm 0.30$ & $0.07 \pm 0.24^{\S}$ & $0.14 \pm 0.08^{\S}$ & NS & $P=0.0001$ & NS \\
\hline Leucine & $-1.79 \pm 0.54$ & $-1.73 \pm 0.28$ & $-0.01 \pm 0.13^{\S}$ & $-0.02 \pm 0.08^{\S}$ & NS & $P=0.001$ & NS \\
\hline Lysine & $-0.26 \pm 0.90$ & $-3.13 \pm 0.43^{\ddagger}$ & $-0.03 \pm 0.28$ & $-0.11 \pm 0.09^{\S}$ & NS & NS & NS \\
\hline Methionine & $-0.27 \pm 0.09$ & $-0.20 \pm 0.05$ & $0.08 \pm 0.06^{\S}$ & $0.08 \pm 0.04^{\S}$ & NS & $P=0.001$ & NS \\
\hline Phenylalanine & $-0.75 \pm 0.21$ & $-0.19 \pm 0.20$ & $-0.10 \pm 0.15$ & $-0.19 \pm 0.07$ & NS & NS & NS \\
\hline Threonine & $0.29 \pm 0.26$ & $0.40 \pm 0.26$ & $0.47 \pm 0.52$ & $0.80 \pm 0.29$ & NS & NS & NS \\
\hline Valine & $-1.76 \pm 0.51$ & $-1.48 \pm 0.27$ & $-0.10 \pm 0.15^{\S}$ & $-0.07 \pm 0.06^{\S}$ & NS & $P=0.002$ & NS \\
\hline \multicolumn{8}{|c|}{ Non-essential amino acids } \\
\hline Alanine & $-0.10 \pm 0.25$ & $0.26 \pm 0.15$ & $0.30 \pm 0.11$ & $0.13 \pm 0.10$ & NS & NS & NS \\
\hline Asparagine & $0.22+0.26$ & $0.18+0.35$ & $0.02+0.08$ & $0.06+0.09$ & NS & NS & NS \\
\hline Aspartate & $0.22 \pm 0.36$ & $0.94 \pm 0.54$ & $0.09 \pm 0.14$ & $-0.23 \pm 0.05^{\neq, \S}$ & NS & NS & NS \\
\hline Cysteine & $1.12 \pm 0.29$ & $1.30 \pm 0.41$ & $0.18 \pm 0.14^{\S}$ & $0.13 \pm 0.07$ & NS & $P=0.007$ & NS \\
\hline Glutamate & $-0.83 \pm 0.30$ & $0.16 \pm 0.31^{\neq}$ & $0.15 \pm 0.10$ & $0.15 \pm 0.12$ & NS & NS & NS \\
\hline Glycine & $-4.26 \pm 1.29$ & $-5.77 \pm 1.84$ & $1.47 \pm 1.41^{\S}$ & $1.72 \pm 0.57^{\S}$ & NS & $P=0.0001$ & NS \\
\hline Proline & $-3.10 \pm 0.86$ & $-0.42 \pm 0.91$ & $1.18 \pm 0.40^{\S}$ & $0.64 \pm 0.17$ & NS & $P=0.008$ & NS \\
\hline Serine & $0.81 \pm 0.27$ & $-0.12 \pm 0.39$ & $0.13 \pm 0.20$ & $-0.50 \pm 0.14^{\ddagger}$ & $P=0.036$ & NS & NS \\
\hline Tyrosine & $-0.40 \pm 0.14$ & $-0.61 \pm 0.20$ & $-0.05 \pm 0.09$ & $-0.17 \pm 0.03$ & NS & $P=0.03$ & NS \\
\hline
\end{tabular}

Measurements were performed on F2 blastocysts from 4- and 12-month control and restricted cohorts. Metabolite concentrations expressed as production (positive values) or consumption (negative values) relative to the media only sample. All data are expressed as mean \pm S.E.M.; $n=10-40$ blastocysts/group from $n=6$ females/group. $P<0.05$ vs 4 -month cohort (main effect), ${ }^{*} P<0.05$ vs control group (following significant interaction) and ${ }^{\dagger} P<0.05$ vs 4 -month cohort (following significant interaction). ${ }^{\ddagger} P<0.05$ vs control and ${ }^{\S} P<0.05$ vs 4 -month cohort.

growth-restricted mothers at 4 months of age (Mazzuca et al. 2010, Gallo et al. 2012b). The onset and timing of these alterations may affect next-generation embryonic and fetal development.

\section{Accelerated growth in F2 blastocysts}

F2 restricted blastocysts accelerate growth when placed into in vitro culture, $24 \mathrm{~h}$ after retrieval. This growth was associated with a greater TE cell number, which may be responsible for the increase in lactate production. Significantly, over-production of lactate alone has been correlated with lower implantation potential in mouse blastocysts grown in vitro (Lane \& Gardner 1996). Previous studies using rat embryos have indicated that nutrient imbalances can affect rat embryo metabolism and alter normal cellular function (Lane \& Gardner 1998). Adaptation to the in vitro culture environment is reported to be associated with a higher ratio of TE to ICM, and as a result reduced viability (Hurst et al. 1993). Accelerated blastocyst and increased total cell number, attributed to greater TE cell number, may therefore be indicative of an adaptation to the culture environment in order to maintain the integrity of the ICM.

When F2 restricted blastocysts were placed in outgrowth culture, alterations in carbohydrate and amino acid metabolism were observed. Outgrowth of blastocysts revealed increases in the consumption of amino acids, specifically serine and lysine, which may reflect the metabolic changes detected at $24 \mathrm{~h}$, due to increased lactate secretion, probably from TE cells. Serine consumption has been shown to act on intracellular growth factors and extracellular matrix proteins to favour correct formation and function in placental cells (De et al. 2004). Regulation of serine utilisation may be required for the initial short-term increased growth of F2 restricted blastocysts immediately following flushing, which is then maintained and stabilised at later time-points, reflected as no difference in the outgrowth area of F2 blastocysts. Such alterations in blastocyst metabolism and amino acid profiles that drive cell proliferation and differentiation would have significant implications for the development of the nutrient transport systems within the developing placenta, especially during trophoblast differentiation from the TE (Fowden et al. 2008). Glutamate production was increased, which may reflect reduced intracellular storage within the blastocyst. Glutamate has been reported to be important for placental and fetal metabolism as it generates NADPH for placental fatty acid steroid synthesis (Moores et al. 1994, Vaughn et al. 1995). Human intrauterine growth restriction studies are characterised by reduced fetal plasma concentrations of essential amino acids such as valine, leucine, isoleucine and lysine (Cetin et al. 1988, Avagliano et al. 2012). A reduction in uptake of lysine in the placenta due to reduced system $A$ amino acid transport activity has also been demonstrated in pregnancies complicated by intrauterine growth restriction (Dicke \& Henderson 1988, Jansson et al. 1998). 

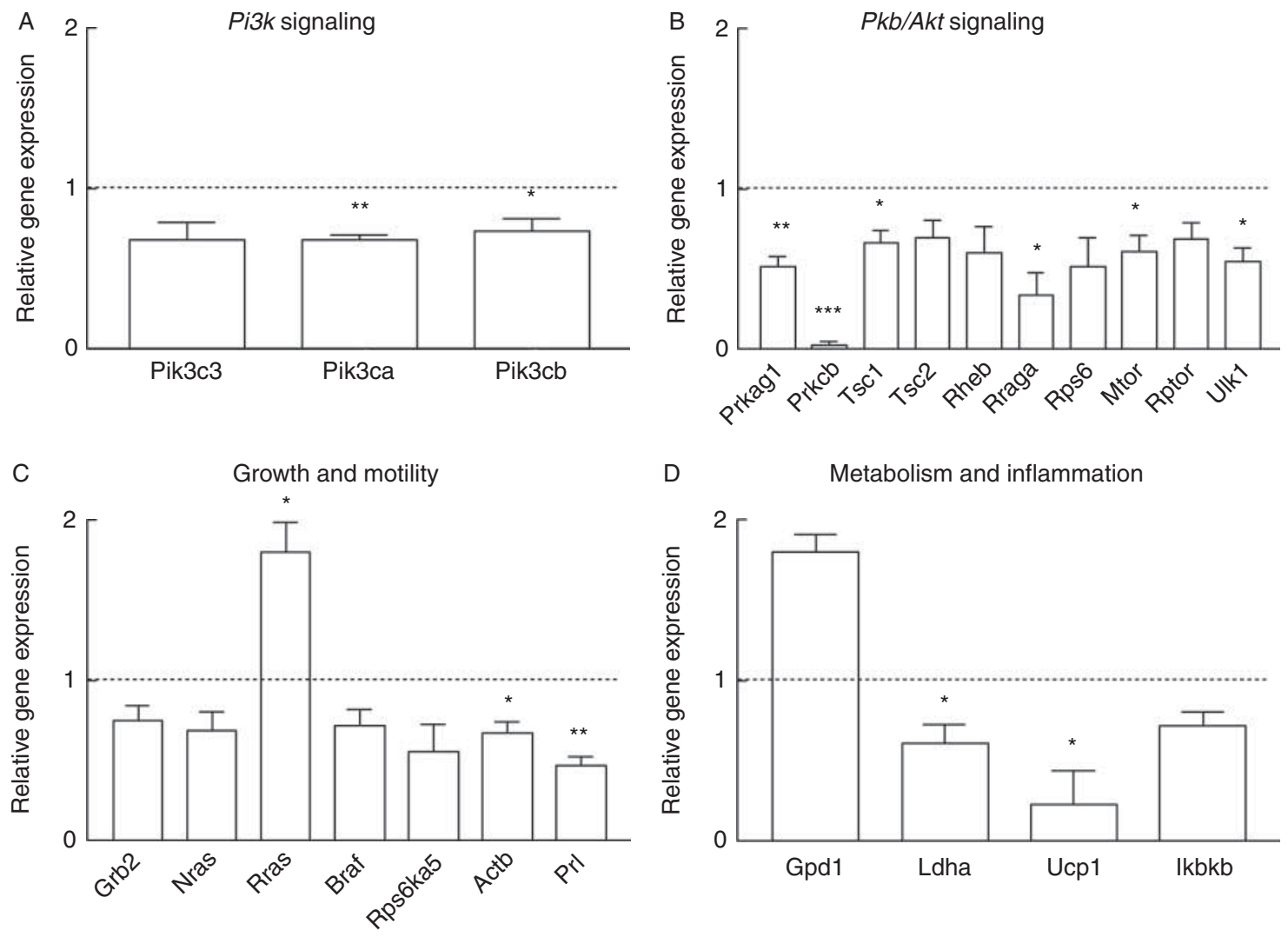

Figure 5 F2 day 4.5 gene expression. Measurements performed on F2 blastocysts from 4-month F1 control and restricted females. Relative gene expression of (A) Pi3k signalling, (B) Pkb/Akt signalling, (C) growth and motility and (D) energy metabolism and inflammation to control level (1, dotted line). All data are expressed as mean \pm S.E.M. There were six females per group and 10-20 blastocysts were pooled from two mothers resulting in three independent biological replicates/group. ${ }^{*} P<0.05$ vs control, ${ }^{*} * P<0.01$ vs control and ${ }^{* * *} P<0.001$ vs control.

It is not known whether alterations in amino acid levels in the F1 restricted uterine environment exist, which may subject the F2 restricted blastocyst to an altered nutrient environment. Low nutrient availability or absorption can alter signalling pathways, which will affect growth and development of the preimplantation blastocyst (Hardy et al. 1989, Brison \& Leese 1991, Lane \& Gardner 1997, Gardner 1998). Conversely, transition from low to high nutrient availability can trigger an adaptive response. Amino acids are also required for TE motility through the activation of mTOR-dependent signal cascades (Martin \& Sutherland 2001, Martin et al. 2003). Regulated by amino acids, the mTOR pathway is responsible for cell growth, proliferation, motility, protein synthesis and transcription. The day 4.5 F2 restricted blastocysts exhibited significant reductions in expression of Pi3k genes, kinases and binding genes (Prkra's (Prk) and TsC1), Mtor and growthrelated genes (Ulk1 and $P r l$ ) in the mTOR growth pathway. The downstream events of $\mathrm{PI} 3 \mathrm{~K}$ signalling are mediated by serine/threonine protein kinase B (PKB/Akt) (Datta et al. 1999, Blume-Jensen \& Hunter 2001, Han \& Carter 2001). Loss or reduction in PKB activity has been related to defects in growth and development of the placenta, placental insufficiency, and results in impaired

Table 4 RT2 profiler arrays.

mTOR signalling

Akt1, Akt1s1, Akt2, Akt3, Cab39, Cab39l, Ccdc88b, Cdc42, Chuk, Ddit4, Ddit4l, Eif4b, Eif4e, Eif4ebp1, Eif4ebp2, Fkbp1a, Fkbp8, Gsk3b, Hif1a, Hras, Hspa4, Igf1, Igfbp3, Ikbkb, Ilk, Ins2, Insr, Irs1, Kras, Mapk1, Mapk3, Mapkap1, Mlst8, Mtor, Myo1c, Nras, Pdpk1, Pik3c3, Pik3ca, Pik3cb, Pik3cd, Pik3cg, Pik3r2, Pld1, Pld2, Ppp2ca, Ppp2r2b, Ppp2r4, Prkaa1, Prkaa2, Prkab1, Prkab2, Prkag1, Prkag2, Prkag3, Prkca, Prkcb, Prkce, Prkcg, Pten, Rheb, Rhoa, Rps6, Rps6ka1, Rps6ka2, Rps6ka5, Rps6kb1, Rps6kb2, Rptor, Rraga, Rragb, Rragc, Rragd, Sgk1, Stk11, Tp53, Tsc1, Tsc2, Ulk1, Vegfa, Vegfb, Vegfc, Ywhaq, Actb, B2m Hprt1, Ldha, and Rplp1
Insulin signalling

Acaca, Acox1, Adra1d, Aebp1, Akt1, Akt2, Akt3, Araf, Bcl2l1, Braf, Cap1, Cbl, Cebpa, Cebpb, Cfd, Dok1, Dok2, Dok3, Dusp14, Eif2b1, Eif4ebp1, Ercc1, Fasn, Fbp1, Fos, Frs2, Frs3, G6pc, Gab1, Gcg, Gck, Gpd1, Grb10, Grb2, Gsk3b, Hk2, Hras, Igf1r, Igf2, Igfbp1, Ins1, Ins2, Insl3, Insr, Irs1, Irs2, Jun, Klf10, Kras, Ldlr, Lep, Map2k1, Mapk1, Mtor, Nos2, Npy, Pck2, Pdpk1, Pik3ca, Pik3cb, Pik3r2, Pklr, Pparg, Ppp1ca, Prkcg, Prkcz, Prl, Ptpn1, Raf1, Retn, Rps6ka1, Rras, Rras2, Serpine1, Shc1, Slc27a4, Slc2a1, Slc2a4, Sos1, Srebf1, Tg, Ucp1, Vegfa, Actb, B2m, Hprt1, Ldha and Rplp1 
fetal growth (Yang et al. 2003). Reduced mTORC1 activity was reported in F1 mouse blastocysts from mothers subjected to maternal undernutrition (0-4.25 days) during pregnancy (Eckert et al. 2012). As gene expression analysis was performed on blastocysts retrieved from F1 growth-restricted females, this clearly highlights preexisting (epi)genetic alterations that could affect blastocyst metabolism. Limited availability of blastocyst material precluded validation of alterations in protein expression. Epigenetic modifications to F1 germ cells or alterations in $\mathrm{F} 1$ germ cells, due to the initial insult of growth restriction, may directly affect F2 blastocyst growth and development and consequently placental and fetal growth.

\section{Age-related alterations in F2 blastocysts}

'Second-hits', such as advanced maternal age, are known to highlight growth restriction phenotypes in female offspring (Nenov et al. 2000). However, we have demonstrated that with advanced maternal age, basal glucose homoeostasis, ovarian function and reproductive potential remain normal in the rat (Gallo et al. 2012c). We have previously reported that advanced maternal age, regardless of growth restriction, results in reduced F2 fetal weight (E20) and litter size (Gallo et al. 2012c). These data indicate that although mating success appears normal in aged females, it is not necessarily a reflection on ovarian function and oocyte, as fetal loss can also be attributed to inadequate placental function.

F1 growth-restricted female rats, with advanced age at conception, produced blastocysts with delayed morphological development and lower cell numbers, which is likely to be attributed to lower TE cell number. The same blastocysts also showed an unusual adaptive metabolic response, this time reflected in an increased glucose uptake, but no change in lactate output. This is curious, as increased glucose uptake correlates positively with blastocyst implantation potential in the mouse and human (Gardner et al. 2011). In our case, the higher glucose consumption in blastocysts with lower TE cell numbers is potentially a very sudden adaptive response to meet the demands of timely blastocoel expansion. Indeed, the speed of blastocoel fluid accumulation is positively correlated with glucose uptake in rat blastocysts (Brison \& Leese 1994). Furthermore, glucose uptake may lead to increased glucose accumulation in the blastocoel itself, rather than being metabolised (Brison et al. 1993), which would explain the lack of change in lactate production. The glucose adaptation may also be reflective of the sustained alterations in carbohydrate and amino acid metabolism observed during blastocyst outgrowth. Of note is the reversal of aspartate levels from its production in the aged restricted blastocyst outgrowths, to its consumption in the controls. Aspartate is highly consumed by mouse blastocysts, and blockage of this amino acid from entering the citric acid cycle has been reported to lead to impaired fetal development (Mitchell et al. 2009).

Altered carbohydrate metabolism has similarly been linked to abnormalities in fetal development and in some cases loss of pregnancy in both humans and murine models (Jurisicova et al. 1998, Harton et al. 2013). Studies have highlighted that oocytes and blastocysts from older females present with chromosomal abnormalities or maladaptation of the embryo in the absence of chromosomal abnormalities (Munne et al. 1995, 2007, Harton et al. 2013), which may explain the reduction in size of F2 littermates from aged F1 female rats, as reported previously (Gallo et al. 2012c). Furthermore, DNA damage has also been correlated with deficits in metabolic activity in preimplantation embryos (Sturmey et al. 2009). Collectively, these data are indicative of cell stress responses, and highlight that F2 blastocysts from aged females require more time to adapt, depending on the degree of physiological deficit. Expression of genes related to growth, development and metabolism may have also been exacerbated by advanced maternal age; however, future studies and new cohorts are required to establish this. Future studies characterising maternal metabolic status and uterine fluid composition in early pregnancy in aged females born of normal birth weight and born small may provide mechanistic insights into age-reported effects.

\section{Transgenerational transmission of growth restriction}

The maternal uterine microenvironment and alterations in pregnancy adaptations can programme the inheritance of diseases to the next generation (Gallo et al. 2012a). How the maternal environment influences the entirety of embryonic, fetal and placental growth, development and function remains unknown. Future studies need to focus on alterations in pregnancy adaptations during all stages from conception to term. Comprehensive biochemical characterisation of $\mathrm{F} 1$ follicular and uterine fluid will be necessary to identify key nutrients that may affect oocyte and embryo quality and programme developmental competence.

This study has illustrated that the F2 blastocyst, derived via the maternal line of growth restriction, has alterations in development and metabolism, which has the potential to alter the course of both placental and fetal function and development. A number of mechanisms for transgenerational transmission of diseases have been proposed. These include direct exposure of germ cells from the F1 fetus, inherited through persistent epigenetic modifications of parental germ cells and/or abnormal pregnancy adaptations, which include the development of glucose intolerance during late gestation (Gallo et al. 2012a). The maternal environment could also metabolically programme the embryo via reproductive tract factors, directly affecting embryo function and implantation events. In order to address as to how true 
transgenerational transmission occurs, a number of studies need to be applied in light of these new data. These include analyses of the F2 restricted blastocyst derived via the paternal line of transmission, as it would delineate between epigenetic modifications and direct exposure of F1 germ cells to direct influences of the maternal environment and, importantly, characterising the F3 offspring in order to verify true transgenerational transmission.

\section{Declaration of interest}

The authors declare that there is no conflict of interest that could be perceived as prejudicing the impartiality of the research reported.

\section{Funding}

This study was supported by the NHMRC project grant (APP1045602) to M E Wlodek and D K Gardner, N J Hannan received support from the NHMRC Early Career Research fellowship (628927). J S Master was supported by the Fay Marles Scholarship from the University of Melbourne and by an MMI-CSIRO scholarship.

\section{References}

Anderson CM, Lopez F, Zimmer A \& Benoit JN 2006 Placental insufficiency leads to developmental hypertension and mesenteric artery dysfunction in two generations of Sprague-Dawley rat offspring. Biology of Reproduction 74 538-544. (doi:10.1095/biolreprod.105.045807)

Avagliano L, Garo C \& Marconi AM 2012 Placental amino acids transport in intrauterine growth restriction. Journal of Pregnancy 2012972562. (doi:10.1155/2012/972562)

Barker DJP 1995 Fetal origins of coronary heart disease. BMJ 311 171-174. (doi:10.1136/bmj.311.6998.171)

Bertram C, Khan O, Ohri S, Phillips DI, Matthews SG \& Hanson MA 2008 Transgenerational effects of prenatal nutrient restriction on cardiovascular and hypothalamic-pituitary-adrenal function. Journal of Physiology 586 2217-2229. (doi:10.1113/jphysiol.2007.147967)

Blume-Jensen P \& Hunter T 2001 Oncogenic kinase signalling. Nature 411 355-365. (doi:10.1038/35077225)

Brison DR \& Leese HJ 1991 Energy metabolism in late preimplantation rat embryos. Journal of Reproduction and Fertility 93 245-251. (doi:10.1530/jrf.0.0930245)

Brison DR \& Leese HJ 1994 The role of exogenous energy substrates in blastocoele fluid accumulation in the rat. Zygote 2 69-77. (doi:10.1017/ S0967199400001787)

Brison DR, Hewitson LC \& Leese HJ 1993 Glucose, pyruvate, and lactate concentrations in the blastocoel cavity of rat and mouse embryos. Molecular Reproduction and Development 35 227-232. (doi:10.1002/ mrd.1080350303)

Cetin I, Marconi AM, Bozzetti P, Sereni LP, Corbetta C, Pardi G \& Battaglia FC 1988 Umbilical amino acid concentrations in appropriate and small for gestational age infants: a biochemical difference present in utero. American Journal of Obstetrics and Gynecology 158 120-126. (doi:10.1016/0002-9378(88)90792-2)

Craig A, Cloarec O, Holmes E, Nicholson JK \& Lindon JC 2006 Scaling and normalization effects in NMR spectroscopic metabonomic data sets. Analytical Chemistry 78 2262-2267. (doi:10.1021/ac0519312)

Datta SR, Brunet A \& Greenberg ME 1999 Cellular survival: a play in three Akts. Genes and Development 13 2905-2927. (doi:10.1101/gad. 13.22.2905)

De Luca A, De Falco M, Fedele V, Cobellis L, Mastrogiacomo A, Laforgia V, Tuduce IL, Campioni M, Giraldi D, Paggi MG et al. 2004 The serine protease HtrA1 is upregulated in the human placenta during pregnancy. Journal of Histochemistry and Cytochemistry 52 885-892. (doi:10.1369/ jhc.3A6186.2004)

Dicke JM \& Henderson GI 1988 Placental amino acid uptake in normal and complicated pregnancies. American Journal of the Medical Sciences 295 223-227. (doi:10.1097/00000441-198803000-00012)

Eckert J, Porter R, Watkins AJ, Burt E, Brooks S, Leese HJ, Humpherson PG, Cameron IT \& Fleming TP 2012 Metabolic induction and early responses of mouse blastocyst developmental programming following maternal low protein diet affecting life-long health. PLOS ONE 7 e52791. (doi:10.1371/journal.pone.0052791)

Eriksson JG, Forsén T, Tuomilehto J, Osmond C \& Barker DJP 2001 Early growth and coronary heart disease in later life: longitudinal study. BMJ 322 948-953. (doi:10.1136/bmj.322.7292.948)

Fowden AL, Forhead AJ, Coan PM \& Burton GJ 2008 The placenta and intrauterine programming. Journal of Neuroendocrinology 20 439-450. (doi:10.1111/j.1365-2826.2008.01663.x)

Gallo LA, Tran M, Master JS, Mortiz KM \& Wlodek ME 2012a Maternal adaptations and inheritance in the transgenerational programming of adult disease. Cell and Tissue Research 349 863-880. (doi:10.1007/ s00441-012-1411-y)

Gallo LA, Tran M, Moritz KM, Mazzuca MQ, Parry LJ, Westcott KT, Jefferies AJ, Cullen-McEwen LA \& Wlodek ME 2012b Cardio-renal and metabolic adaptations during pregnancy in female rats born small: implications for maternal health and second generation fetal growth. Journal of Physiology $\mathbf{5 9 0}$ 617-630. (doi:10.1113/jphysiol.2011. 219147)

Gallo LA, Tran M, Moritz KM, Jefferies AJ \& Wlodek ME 2012c Pregnancy in aged rats that were born small: cardiorenal and metabolic adaptations and second-generation fetal growth. FASEB Journal 26 4337-4347. (doi:10.1096/fj.12-210401)

Gallo LA, Tran M, Cullen-McEwen LA, Denton KM, Jefferies AJ, Moritz KM \& Wlodek ME 2013 Transgenerational programming of fetal nephron deficits and sex-specific adult hypertension in rats. Reproduction, Fertility, and Development 26 1032-1043. (doi:10.1071/RD13133)

Gardner DK 1998 Changes in requirements and utilization of nutrients during mammalian preimplantation embryo development and their significance in embryo culture. Theriogenology 49 83-102. (doi:10. 1016/S0093-691X(97)00404-4)

Gardner DK 2007 Noninvasive metabolic assessment of single cells. Methods in Molecular Medicine 132 1-9.

Gardner DK \& Lane M 2007 Embryo culture systems. In In Vitro Fertilization: A Practical Approach, pp 221-282. Ed. DK Gardner. New York, NY: Informa Healthcare.

Gardner DK \& Lane M 2014 Mammalian preimplantation embryo culture. Methods in Molecular Biology 1092 167-182.

Gardner DK \& Leese HJ 1987 Assessment if embryo viability prior to transfer by non-invasive measurement of glucose uptake. Journal of Experimental Zoology 242 103-105. (doi:10.1002/jez.1402420115)

Gardner DK, Lane M, Stevens J, Schlenker T \& Schoolcraft WB 2000 Blastocyst score affects implantation and pregnancy outcome: towards a single blastocyst transfer. Fertility and Sterility 73 1155-1158. (doi:10. 1016/S0015-0282(00)00518-5)

Gardner DK, Wale PL, Collins R \& Lane M 2011 Glucose consumption of single post-compaction human embryos is predictive of embryo sex and live birth outcome. Human Reproduction 26 1981-1986. (doi:10.1093/ humrep/der143)

Gindoff PR \& Jewelewicz R 1986 Reproductive potential in the older woman. Fertility and Sterility 46 989-1001.

Gook DA, Edgar DH, Lewis K, Sheedy JR \& Gardner DK 2014 Impact of oxygen concentration on adult murine pre-antral follicle development in vitro and the corresponding metabolic profile. Molecular Human Reproduction 20 31-41. (doi:10.1093/molehr/gat062)

Haavaldsen C, Samuelsen SO \& Eskild A 2011 The association of maternal age with placental weight: a population-based study of 536,954 pregnancies. BJOG: an International Journal of Obstetrics and Gynaecology 118 1470-1476. (doi:10.1111/j.1471-0528.2011. 03053.x)

Han VK \& Carter AM 2001 Control of growth and development of the feto-placental unit. Current Opinion in Pharmacology 1 632-640. (doi:10.1016/S1471-4892(01)00108-4) 
Handyside AH \& Hunter S 1984 A rapid procedure for visualising the inner cell mass and trophectoderm nuclei of mouse blastocysts in situ using polynucleotide-specific fluorochromes. Journal of Experimental Zoology 231 429-434. (doi:10.1002/jez.1402310317)

Hannan NJ, Paiva P, Meehan KL, Rombauts LJF, Gardner DK \& Salamonsen LA 2011 Analysis of fertility-related soluble mediators in human uterine fluid identifies VEGF as a key regulator of embryo implantation. Endocrinology 152 4948-4956. (doi:10.1210/en.2011-1248)

Hardy K, Handyside AH \& Winston RM 1989 The human blastocyst: cell number, death and allocation during late preimplantation development in vitro. Development 107 597-604.

Harton GL, Munne S, Surrey M, Grifo J, Kaplan B, McCulloh DH, Griffin DK \& Wells D 2013 Diminished effect of maternal age on implantation after preimplantation genetic diagnosis with array comparative genomic hybridization. Fertility and Sterility 100 1695-1703. (doi:10.1016/j.fertnstert.2013.07.2002)

Heijmans BT, Tobi EW, Stein AD, Putter H, Blauw GJ, Susser ES, Slagboom PE \& Lumey LH 2008 Persistent epigenetic differences associated with prenatal exposure to famine in humans. PNAS $\mathbf{1 0 5}$ 17046-17049. (doi:10.1073/pnas.0806560105)

Hurst PR, Leeuwenberg BR \& Ellis LM 1993 Stereological study of mouse uterine and in vitro grown blastocysts: cell numbers and volumes. Anatomical Record 236 411-416. (doi:10.1002/ar.1092360216)

Jansson T, Scholtbach V \& Powell TL 1998 Placental transport of leucine and lysine is reduced in intrauterine growth restriction. Pediatric Research 44 532-537. (doi:10.1203/00006450-199810000-00011)

Jurisicova A, Rogers I, Fasciani A, Casper RF \& Varmuza S 1998 Effect of maternal age and conditions of fertilization on programmed cell death during murine preimplantation embryo development. Molecular Human Reproduction 4 139-145. (doi:10.1093/molehr/4.2.139)

Kwong WY, Wild AE, Roberts P, Willis AC \& Fleming TP 2000 Maternal undernutrition during the preimplantation period of rat development causes blastocyst abnormalities and programming of postnatal hypertension. Development 127 4195-4202.

Lane M \& Gardner DK 1996 Selection of viable mouse blastocysts prior to transfer using a metabolic criterion. Human Reproduction $\mathbf{1 1}$ 1975-1978. (doi:10.1093/oxfordjournals.humrep.a019527)

Lane M \& Gardner DK 1997 Differential regulation of mouse embryo development and viability by amino acids. Journal of Reproduction and Fertility 109 153-164. (doi:10.1530/jrf.0.1090153)

Lane M \& Gardner DK 1998 Amino acids and vitamins prevent cultureinduced metabolic perturbations and associated loss of viability of mouse blastocysts. Human Reproduction 13 991-997. (doi:10.1093/ humrep/13.4.991)

Lane M \& Gardner DK 2004 Preparation of gametes, in vitro maturation, in vitro fertilization, embryo recovery and transfer. In A Laboratory Guide to the Mammalian Embryo, pp 22-40. Eds DK Gardner, M Lane \& AJ Watson. New York, NY: Oxford University Press.

Lea RG, McCracken JE, McIntyre SS, Smith W \& Baird JD 1996 Disturbed development of the preimplantation embryo in the insulin-dependent diabetic BB/E rat. Diabetes 45 1463-1470. (doi:10.2337/diab.45.11.1463)

Martin PM \& Sutherland AE 2001 Exogenous amino acids regulate trophectoderm differentiation in the mouse blastocyst through an mTOR-dependent pathway. Developmental Biology 240 182-193. (doi:10.1006/dbio.2001.0461)

Martin PM, Sutherland AE \& Van Winkle LJ 2003 Amino acid transport regulates blastocyst implantation. Biology of Reproduction 69 1101-1108. (doi:10.1095/biolreprod.103.018010)

Mazzuca MQ, Wlodek ME, Dragomir NM, Parkington HC \& Tare M 2010 Uteroplacental insufficiency programs regional vascular dysfunction and alters arterial stiffness in female offspring. Journal of Physiology $\mathbf{5 8 8}$ 1997-2010. (doi:10.1113/jphysiol.2010.187849)

McMillen IC \& Robinson JS 2005 Developmental origins of the metabolic syndrome: prediction, plasticity and programming. Physiological Reviews 85 571-633. (doi:10.1152/physrev.00053.2003)

Mitchell M, Schulz SL, Armstrong DT \& Lane M 2009 Metabolic and mitochondrial dysfunction in early mouse embryos following maternal dietary protein intervention. Biology of Reproduction 80 622-630. (doi:10.1095/biolreprod.108.072595)

Moley KH, Chi MM \& Mueckler MM 1998 Maternal hyperglycemia alters glucose transport and utilization in mouse preimplantation embryos. American Journal of Physiology 275 E38-E47.
Moores RR Jr, Vaughn PR, Battaglia FC, Fennessey PV, Wilkening RB \& Meschia G 1994 Glutamate metabolism in fetus and placenta of lategestation sheep. American Journal of Physiology 267 R89-R96.

Moritz KM, Mazzuca MQ, Siebel AL, Mibus A, Arena D, Tare M, Owens JA \& Wlodek ME 2009 Uteroplacental insufficiency causes a nephron deficit, modest renal insufficiency but no hypertension with ageing in female rats. Journal of Physiology 587 2635-2646. (doi:10.1113/ jphysiol.2009.170407)

Munne S, Alikani M, Tomkin G, Grifo J \& Cohen J 1995 Embryo morphology, developmental rates, and maternal age are correlated with chromosome abnormalities. Fertility and Sterility 64 382-391.

Munne S, Chen S, Colls P, Garrisi J, Zheng X, Cekleniak N, Lenzi M, Hughes P, Fischer J, Garrisi M et al. 2007 Maternal age, morphology, development and chromosome abnormalities in over 6000 cleavagestage embryos. Reproductive Biomedicine Online 14 628-634. (doi:10. 1016/S1472-6483(10)61057-7)

Nenov VD, Taal MW, Sakharova OV \& Brenner BM 2000 Multi-hit nature of chronic renal disease. Current Opinion in Nephrology and Hypertension 9 85-97. (doi:10.1097/00041552-200003000-00001)

Oh SH, Miyoshi K \& Funahashi H 1998 Rat oocytes fertilized in modified rat 1-cell embryo culture medium containing a high sodium chloride concentration and bovine serum albumin maintain developmental ability to the blastocyst stage. Biology of Reproduction 59 884-889. (doi:10.1095/biolreprod59.4.884)

Painter RC, Osmond C, Gluckman P, Hanson M, Phillips DI \& Roseboom TJ 2008 Transgenerational effects of prenatal exposure to the Dutch famine on neonatal adiposity and health in later life. BJOG: an International Journal of Obstetrics and Gynaecology 115 1243-1249. (doi:10.1111/j. 1471-0528.2008.01822.x)

Sheedy JR, Ebeling PR, Gooley PR \& McConville MJ 2010 A sample preparation protocol for ${ }^{1} \mathrm{H}$ nuclear magnetic resonance studies of watersoluble metabolites in blood and urine. Analytical Biochemistry 398 263-265. (doi:10.1016/j.ab.2009.11.027)

Sturmey RG, Hawkhead JA, Barker EA \& Leese HJ 2009 DNA damage and metabolic activity in the preimplantation embryo. Human Reproduction 24 81-91. (doi:10.1093/humrep/den346)

Torrens C, Poston L \& Hanson MA 2008 Transmission of raised blood pressure and endothelial dysfunction to the F2 generation induced by maternal protein restriction in the F0, in the absence of dietary challenge in the F1 generation. British Journal of Nutrition 100 760-766. (doi:10. 1017/S0007114508921747)

Tran M, Gallo LA, Jefferies AJ, Moritz KM \& Wlodek ME 2013 Transgenerational metabolic outcomes associated with uteroplacental insufficiency. Journal of Endocrinology 217 105-118. (doi:10.1530/JOE12-0560)

Vaughn PR, Lobo C, Battaglia FC, Fennessey PV, Wilkening RB \& Meschia G 1995 Glutamine-glutamate exchange between placenta and fetal liver. American Journal of Physiology 268 E705-E711.

Wadley GD, Siebel AL, Cooney GJ, McConell GK, Wlodek ME \& Owens JA 2008 Uteroplacental insufficiency and reducing litter size alters skeletal muscle mitochondrial biogenesis in a sex specific manner in the adult rat. American Journal of Physiology 294 E861-E869.

Watkins AJ, Papenbrock T \& Fleming TP 2008a The preimplantation embryo: handle with care. Seminars in Reproductive Medicine 26 175-185. (doi:10.1055/s-2008-1042956)

Watkins AJ, Ursell E, Panton R, Papenbrock T, Hollis L, Cunningham C, Wilkins A, Perry VH, Sheth B, Kwong WY et al. 2008b Adaptive responses by mouse early embryos to maternal diet protect fetal growth but predispose to adult onset disease. Biology of Reproduction $\mathbf{7 8}$ 299-306. (doi:10.1095/biolreprod.107.064220)

Watkins AJ, Wilkins A, Cunningham C, Perry VH, Seet MJ, Osmond C, Eckert JJ, Torrens C, Cagampang FR, Cleal J et al. 2008c Low protein diet fed exclusively during mouse oocyte maturation leads to behavioural and cardiovascular abnormalities in offspring. Journal of Physiology $\mathbf{5 8 6}$ 2231-2244. (doi:10.1113/jphysiol.2007.149229)

Webb-Robertson BJ, Lowry DF, Jarman KH, Harbo SJ, Meng QR, Fuciarelli AF, Pounds JG \& Lee KM 2005 A study of spectral integration and normalization in NMR-based metabonomic analyses. Journal of Pharmaceutical and Biomedical Analysis 39 830-836. (doi:10.1016/j. jpba.2005.05.012)

Wlodek ME, Westcott KT, O'Dowd R, Serruto A, Wassef L, Moritz KM \& Moseley JM 2005 Uteroplacental restriction in the rat impairs 
fetal growth in association with alterations in placental growth factors including PTHrP. American Journal of Physiology 288 R1620-R1627.

Wlodek ME, Mibus A, Tan A, Siebel AL, Owens JA \& Moritz KM 2007 Normal lactational environment restores nephron endowment and prevents hypertension after placental restriction in the rat. Journal of the American Society of Nephrology 18 1688-1696. (doi:10.1681/ASN.2007010015)

Wlodek ME, Westcott K, Siebel AL, Owens JA \& Moritz KM 2008 Growth restriction before or after birth reduces nephron number and increases blood pressure in male rats. Kidney International 74 187-195. (doi:10. 1038/ki.2008.153)
Yang ZZ, Tschopp O, Hemmings-Mieszczak M, Feng J, Brodbeck D, Perentes E \& Hemmings BA 2003 Protein kinase Ba/Akt1 regulates placental development and fetal growth. Journal of Biological Chemistry 278 32124-32131. (doi:10.1074/jbc.M302847200)

Received 27 November 2014

First decision 14 January 2015

Revised manuscript received 19 January 2015

Accepted 9 February 2015 